\title{
475500 - PLASMA CONCENTRATIONS OF INHALED MILRINONE IN CARDIAC PATIENTS
}

\author{
Anne Quynh Nhu Nguyen, BSc. ${ }^{1}$, André Denault, md², Yves Théorêt, \\ BPharm.PhD. ${ }^{3}$, Chunlin Chen, M.D. ${ }^{1}$, Yoan Lamarche, MD.MSc. ${ }^{4}$, Louis Perrault, \\ md $^{4}$, France Varin, BPharm.PhD. ${ }^{1}$ \\ 1. Pharmacie, Université de Montréal, Montreal, QC, Canada \\ 2. Anesthesiology, Montreal Heart Institut, Montreal, QC, Canada \\ 3. Pharmacologie, Université de Montreal, Montreal, QC, Canada \\ 4. Cardiac surgery, Montreal Heart Institut, Montreal, QC, Canada
}

Introduction: Milrinone is a vasoactive drug administered intravenously or through inhalation to patients undergoing cardiac surgery under cardiopulmonary bypass (CPB) for the treatment and prevention of pulmonary hypertension $(\mathrm{PH})$ associated with difficult separation from bypass (DSB).(1)(2) Targeted steady-state concentrations during intravenous administration are considered to be 100-300 ng/ml.(3) However, when given intravenously milrinone is associated with a high occurrence of systemic hypotension while this is not the case after inhalation.(4) The blood concentrations of milrinone administered through inhalation have never been measured but the absence of hypotension could be secondary to lower systemic concentrations. Our objective was to confirm that the safer profile of inhaled milrinone could be secondary to lower systemic exposure.

Methods: A pilot observational study was carried out in patients scheduled for elective cardiac surgery requiring CPB. After approval by the research and ethics committee and with permission from Health Canada, informed consent was obtained in 12 patients admitted at the Montreal Heart Institute. Patients with preoperative $\mathrm{PH}$ and for whom administration of inhaled milrinone was indicated were enrolled. Milrinone (5 mg) was administered before CPB (Pre-CPB) by nebulization (conventional or ultrasonic) over 15 min. Arterial blood samples were obtained before starting inhalation (time zero), at 20, 25, 30 min thereafter, and immediately after CPB (Post-CPB). Milrinone concentrations were determined by HPLC with UV detection with a lower limit of quantification of 1.25 $\mathrm{ng} / \mathrm{ml}$.

Results: In all patients, peak systemic levels of milrinone are below $80 \mathrm{ng} / \mathrm{ml}$.

Discussion: Because the first sample was drawn 5 min after stopping inhalation, peak concentrations could have been underestimated. However, these concentrations remain significantly below those measured after intravenous administration of milrinone. In view of the reported low incidence of systemic hypotension associated with 15 min inhalation, our pilot study suggests that a negligible systemic availability may explain the higher therapeutic index of inhaled milrinone.

References: (1) Lamarche Y, Perrault LP, Maltais S, Tetreault K, Lambert J, Denault AY: Preliminary experience with inhaled milrinone in cardiac surgery. Eur $\mathrm{J}$ Cardiothorac Surg 2007; 31: 1081-7 (2) Denault AY, Lamarche Y, Couture P, Haddad F, Lambert J, Tardif JC, Perrault LP: Inhaled milrinone: a new alternative in cardiac surgery? Semin Cardiothorac Vasc Anesth 2006; 10: 346-60 (3) Woolfrey SG, Hegbrant 
J, Thysell H, Fox PA, Lendrem DW, Lockwood GF, Lasher K, Rogers J, Greenslade D: Dose regimen adjustment for milrinone in congestive heart failure patients with moderate and severe renal failure. J Pharm Pharmacol 1995; 47: 651-5 (4) Jaski BE, Fifer MA, Wright RF, Braunwald E, Colucci WS: Positive inotropic and vasodilator actions of milrinone in patients with severe congestive heart failure. Dose-response relationships and comparison to nitroprusside. J Clin Invest 1985; 75: 643-9 